\title{
Towards a Classification View of Personalized e-Learning with Social Collaboration Support
}

\author{
Amal Al-Abri ${ }^{1}$, Yassine Jamoussi ${ }^{2}$, Zuhoor AlKhanjari ${ }^{3}$, Naoufel Kraiem ${ }^{4}$ \\ Department of Computer Science, Sultan Qaboos University \\ Muscat, Oman
}

\begin{abstract}
With the emergence of Web 2.0 technologies, interaction and collaboration support in the educational field have been augmented. These types of support embrace researchers to enrich the e-learning environment with personalized characteristics with the utilization of the collaboration support outputs. Achieving this requires understanding the existing environments and highlights their eminence. As a result, there are many attempts to state the current status of personalized e-learning environment from different perspectives. However, these attempts targeted a specific view and direction which failed to provide us with the general view of the adoption of personalized e-learning environment with the support of social collaboration tools. This paper provides a classified view of the current status of personalized e-learning environments which incorporate social collaboration tools for providing the personalization feature. The classification adopts four different views to carry out the classification; these views are subject, purpose, method, and tool. The findings show that the utilization of the user-generated contents and social interaction functionalities for personalization is tight and not fully consumed. In short, the potential of providing personalized learning with social interaction and collaboration features remains not fully explored.
\end{abstract}

Keywords-Classification review; collaboration; personalized elearning; social media

\section{INTRODUCTION}

Personalized e-learning environment is becoming more demanding in today's academic world [1]-[3]. According to Heller and his colleagues [4], the aim of personalized learning is to "tailor teaching to individual needs, interests, and aptitude." This form of online learning has the potential to serve the learners by providing a learning-teaching process according to the learner's needs as a medium of adaptation techniques to ensure the most effective knowledge transfer for each learner [5]. Besides, personalizable courseware requires connection with various tools like learning network for collaboration and performing learning tasks/activities. Therefore, by incorporating interactive Web 2.0 technologies like social media, personalized e-learning derived new opportunities in learning with the incorporation of collaborative learning activities [1].

With the emerging technology of web services like web 2.0 tools and enormous adoption of social collaboration tools for learning [6], the possibility of developing an e-learning platform for description, discovery, interaction, collaboration and interoperability of distributed, heterogeneous applications as services has been amplified enormously [7]-[10].
Collaborative learning is one of the learning styles motivated by the emergent of social media tools. According to [11], collaborative learning could be defined as "a variety of educational practices in which interactions among peers constitute the most important factor in learning, although without excluding other factors, such as the learning material and interactions with teachers". The characteristics of social media tools enhanced the adoption of collaborative learning activities in the educational field via the learning environments [12]. The concept of collaborative learning environment requires establishing a networked environment to facilitate active participation, interaction, and collaboration [13]. Besides, it also supports sharing and accessing learning resources among users [14]. The active participation opens the door for students to express themselves and share information related to their knowledge, preferences, and needs either explicitly or implicitly. This information is important to understand the characteristics of the learner. Consequently, provide personalization feature as it is highly demanded in today's educational environments [1], [15]-[17]. Thus, information related to the knowledge on the discussed topic and expressed opinion via like/dislike or textual expression needs to be extracted from social media.

From the scientific researcher's point of view, data-driven approaches to effectively facilitate personalization has only recently begun to emerge within higher education, especially with the integration of social collaboration tools [3]. Creating a personalized path especially with the involvement of social collaboration tools and services increased the amount of data and resources to be filtered and tailed to the learner's needs, which is a costly and complex task [3], [18], [19]. Especially since such involvement requires dealing with unstructured and noisy data generated during the collaboration. Therefore, understanding the integration of social collaboration tools in elearning and the utilization of generated output during the use of these tools towards personalized e-learning is required. This type of investigation helps to understand the current status and adoption of these concepts to guide any further enhancement and development of new systems.

Despite the attempts carried out by different researchers to discuss the use of social collaboration in personalized elearning, their discussions were limited to a specific dimension. For example, they focused on communication and collaboration techniques or user interface mechanisms or analysis techniques. As a result, provide a partial view of the integration which is still insufficient to have a full understanding of this concept. Therefore, this paper is 
attempting to give more advance view of the utilization of social collaboration in the personalized e-learning environment.

The paper is structured as follow: Section 2 discusses the literature review. Section 3 presents the approach proposed to classify the personalized e-learning systems with social collaboration supports systems. Section 4 provides a comparison of seven systems. In Section 5, a detailed discussion of the findings is presented. The paper is concluded in Section 6.

\section{LITERATURE REVIEW}

There have been many attempts by researchers in this field to state the current status of personalized e-learning environment from different perspectives. For example, In [20], the researchers focused on giving an overview of the use of adaptivity in e-learning by investigating whether it has been used and the extent to which it has been used. The researchers concluded that the majority of e-learning systems are not providing adaptivity features. Besides, the limited number of supported ones are not suitable for common e-learning scenarios as they are missing some standard features.

Another researcher like [21] discussed the state of art of personalization, particularly in the learning management system (LMS). This discussion focused on the limited personalization features provided by LMS like user interface and conditional activities feature which is controlled by the teacher to support the learning path.

A systematic review conducted by [22] to investigate the academic achievement in online higher education environments in accordance with the self-regulation (personalization) strategies followed by learners. This review considered some parameters like strategies, academic outcomes, participants, method design, course type \& duration. However, this comprehensive review tackled peer learning as part of collaborative learning only partially.

The researchers in [23] conducted a survey on the employment of artificial intelligence techniques and related topics for adaptive e-learning (personalization). The discussion focused on one view of collaboration in the form of asynchronous or synchronous learning environments. Therefore, the survey is limited in the covered dimension.

As discussed in this section, the above-mentioned attempts, targeted a specific view and direction of personalization which provides a limited view of the personalized e-learning practices especially with the support of social collaboration tools. Therefore, the aim of this paper is to provide a comprehensive view of the current status of personalized e-learning environments which incorporate social collaboration tools for providing the personalization feature. This view will tackle the concept from four different angels as it is going to be discussed in Section 3.

\section{PRoposed Classification VieW}

To investigate the utilization of social collaboration in the field of personalized e-learning, it is more appropriate to view it from different dimensions. This way the whole picture of the utilization will be clear and more understandable. For example, in a particular personalized e-learning system, it is helpful to know the target of the developed system, the reason behind the development, the manner where social collaboration has been integrated and the tools have been used for the collaboration. This can be achieved by classifying the view into different angels to cover the full picture.

The classification of social collaboration supports in the field of personalized e-learning using the web 2.0 functionalities can be derived using the classification framework as in [8]. The framework provides a multidimensional view to classifying personalized e-learning with social collaboration support systems. The view applies a faceted classification approach which can handle a multi-view and flexibility features [24] in analyzing the domain content of the targeted systems. It, as a result, enables the updating of the facet classification by adding new terms, modifying existing ones or even deleting unwanted ones without affecting other facets.

Faceted classification is defining the instantiated attribute classes with different terms. The facets are considered as perspectives, viewpoints, or dimensions of a particular domain. Each facet is measured by a set of relevant attributes. According to [25], "these attributes have values that are defined within a domain, whereby a domain may be a predefined type such as integral or Boolean, an enumerated type $(\{x, y, z\})$, or a structured type (Set $\{x, y\})$ ". The set type allows characterizing the attributes using several values whose elements might belong to the enumerated type. Thus, a given collaboration approach might be positioned within a specific facet with two pairs of (attribute; value).

\section{A. Classification Framework}

The classification in the proposed framework is based on four different views as shown in Fig. 1. Each view captures a particular and relevant aspect of the systems. The four views are What (subject), Why (purpose), How (method), and Which (tool). Each view in the framework consists of a number of facets which present a set of attributes, and the attributes are defined by suitable values. Besides, there is an interconnection between the views which enforce the link between the different views in the framework.

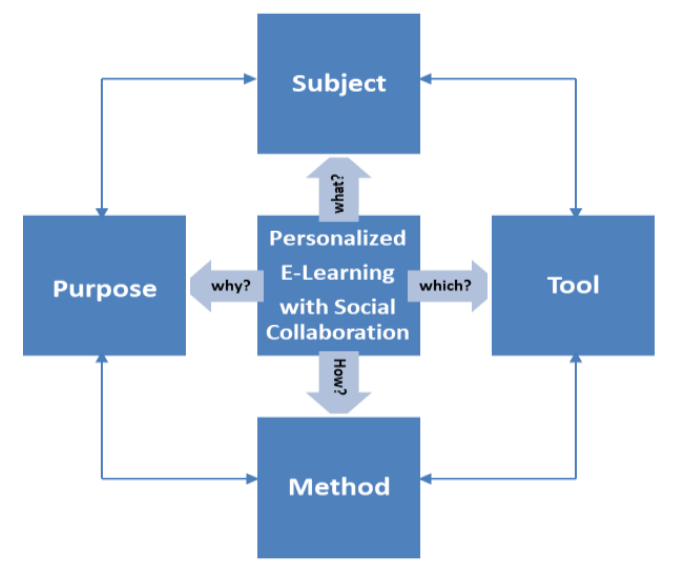

Fig. 1. Classification Framework for Personalized e-learning with Collaboration Support. 


\section{B. Derived Facets from the Existing Framework}

Deriving from the classification framework proposed in our previous publication [8], the selected facets for the classification are depicted in Table I. The facets which represent the social collaboration characteristics in the four views as discussed in [8] give an overview of the attributes describing the different views of the classification framework. For instance, the subject view represents the "what" aspect of the framework by two facets related to the personalized elearning with social collaboration support. These facets are actor facet and adaptability facet. The former consists of four attributes representing the different actors who can play an important role in social collaboration tools. It reflects the personalization aspect of the e-learning system either as a receiver or provider of the learning process. The latter facet represents the level of adaptability as a reflection of the personalization parameters provided by the tool.

The purpose view of the framework deals with the reason behind the development of the tool. In other words, it attempts to answer why the tool has been developed. From the social collaboration perspectives, the services facet is proposed to describe the purpose of the existing tool.

TABLE. I. SELECTED FACETS FROM CLASSIFICATION FRAMEWORK PRESENTED IN [8]

\begin{tabular}{|c|c|c|}
\hline Concept/view & Facet & Attribute (facet representation) \\
\hline \multirow[t]{2}{*}{ Subject View } & Actor Facet & $\begin{array}{l}\text { - Learner: SET (ENUM \{Students, } \\
\text { Employee\}) } \\
\text { - Teacher: SET (ENUM \{Instructor, } \\
\text { Facilitator\}) } \\
\text { - Administrator: SET (ENUM \{Institute, } \\
\text { Developers\}) } \\
\text { - Experts: SET ( ENUM \{Researchers, } \\
\text { Experts\}) }\end{array}$ \\
\hline & $\begin{array}{l}\text { Adaptability } \\
\text { Facet }\end{array}$ & $\begin{array}{l}\text { - Adaptability level: SET:\{High, Medium, } \\
\text { Low }\}\end{array}$ \\
\hline Purpose View & $\begin{array}{l}\text { Services } \\
\text { Facet }\end{array}$ & $\begin{array}{l}\text { - Monitoring: BOOLEAN } \\
\text { - Learner tracking: BOOLEAN } \\
\text { - Visualization: SET (ENUM\{Graphical, } \\
\text { Algorithm\}) } \\
\text { - Grading \& Evaluation: SET } \\
\text { (ENUM\{Scores, Analysis\}) }\end{array}$ \\
\hline Method View & $\begin{array}{l}\text { Collaboration } \\
\text { Methods } \\
\text { Facet }\end{array}$ & $\begin{array}{l}\text { - Interaction: SET (ENUM }\{\text { Collaborative } \\
\text { writing, Communicating chatting and } \\
\text { social interaction, file sharing, } \\
\text { brainstorming, sharing links and } \\
\text { bookmarks, media sharing, computer- } \\
\text { intensive e-learning services\}) } \\
\text { - Integration: SET (ENUM }\{\text { Plugins, Stand- } \\
\text { alone, Mashups\}) }\end{array}$ \\
\hline Tool View & (LOs) Facet & $\begin{array}{l}\text { - Granularity: SET \{aggregation level, } \\
\text { complexity\} } \\
\text { - Authoring: SET \{content (multimedia } \\
\text { objects, real world objects), metadata\} } \\
\text { - Standards: SET \{SCORM, ISM-LD, } \\
\text { IEEE LOM, SOA } \\
\text { - Language: SET }\{\text { language()\} }\end{array}$ \\
\hline
\end{tabular}

The method view describes the "how" angle of the framework. It presents the methods adapted for the social collaboration which provide support to delegate the personalization feature to the learners. Collaboration methods fact derived from the existing framework represents two attributes (interaction and integration) as methods for delivering the social collaboration feature.

The tool view in the classification framework elucidates the "which" part of the framework. This indicates the importance of the tools used by the actors based on the method applied to achieve the purpose of the personalized elearning system. The extracted LOs facet represents the resources as a tool in the social collaboration process to support the delivery of personalized learning resources.

The complete list of the derived facets for each view and their respected attributes are depicted in Table I.

As the vital concept in the classification view presented in this paper is the personalization, there is a need to look closely into the personalization aspect from different angles related to the support derived through the social collaboration tools. Besides, the previous classification focuses on the collaboration concept rather than the personalization aspect. Therefore, advanced facets related to personalized e-learning are generated based on the four views of the classification framework as per the discussion in the next sub-section.

\section{Generated Facets}

In the personalized learning environment (PLE), the Learning place is an aggregation of communication and collaboration tools, shared resources, services, and people [26]. According to Becta, (2007), PLE should also help to satisfy individual needs (personalization). Therefore, when assessing any e-learning environment developed for personalization purpose, there is a need to verify the availability of the following parameters.

- Communication and collaboration: Promoting communication and collaboration are one of the functionalities in e-learning which may enhance the process to provide personalized e-learning environment [26], [27]. Generated data during collaboration can be a valuable source of information to understand the learner's characteristics and concepts under discussion, which will in turn help in providing personalization feature. Referring to the classification framework, this functionality belongs to the method view of the systems. Specifically, the collaboration method facet.

- Resources: Learning resources or objects are the key source of knowledge to be shared between learners during the learning process [28]. Therefore, learning resources considered as an important facet in an elearning environment. For personalized e-learning, learning resources are the package to be delivered to the learners to avoid heterogeneous part of the available resources [29].

- Services: The e-learning environment should facilitate the interaction and management of the learning tool through the availability of vital services, like web 
application for interactions [26], tools for monitoring, tracking learners' progress, visualizing and representing data, analyzing and evaluating the obtained data [10], [27]. The service facet in the purpose view of the classification framework is discussed.

- People: Learners and teachers are the main parties in the learning process. However, when integrating collaboration support, other parties can also be involved in the process, allowing for more engagements, which will eventually help to enrich the discussions. People or actors like friends and experts as discussed in the classification framework.

- Adaptation: adaptation techniques and parameters enlighten the path to follow and the aspects of learners to take under considerations when providing personalization [30]. In the area of collaboration support, the user-generated content is utilized to extract information related to the parameters used for personalization as well as discovering and representing the domain under discussion [7]. Measuring to what extent the system is adaptive to the learners' needs is very important as discussed in the classification framework.

Based on the identified parameters of personalized learning with collaboration support systems and the classification framework proposed to compare collaboration approaches in e-learning, five facets (actor, adaptability, service, collaboration method and LOs) from the four views will be considered. The mapping between the personalized learning environment parameters and the classification framework is depicted in Fig. 2. The dotted area shows the mapping part, displaying the views and the corresponding facets from the classification framework.

To understand the personalized e-learning environment with collaboration support based on the identified facets from the classification framework, the attributes and values for each facet need to be stated. For this comparison, all the attributes and values will be the same, except for the adaptability facet. As the main focus is the personalization aspect in these systems, some attributes need to be added to illustrate how personalization has been carried out in these systems apart from the adaptability level. The added attributes for this purpose are:

- Learner's characteristic which specifies the parameters considered in providing personalization. According to [31], the most popular and useful features which can distinguish the learner as an individual are; the learner's knowledge, interests, goals, background, preferences, and individual traits like (cognitive style and learning style).

- Component that represents the model in a semi/automatically generated during the personalization process. According to [32], the core of the architecture of an adaptive application is formed by three closely linked components: the domain model (DM); the user model (UM); and the adaptation model
(AM). In a learning application, for instance, the user model will keep track of the user's knowledge of each of the concepts in the domain model. The adaptation model defined the rules that state how the adaptation must be performed and the actual adaptation performs by the adaptive engine [32].

- Technique for expressing the methods adopted to provide personalization. The adaptation technologies are adopted from three areas which are intelligent tutoring systems (ITS), adaptive hypermedia (AH), and adaptive collaboration support (ACLS) [33].

The added attributes in the adaptability facet can be classified as the followings:

Characteristic: SET (ENUM \{knowledge, interests, goals, background, preferences, individual traits $\}$ )

Component: SET (ENUM \{domain model, user model, adaptation model\})

Technique: SET (ENUM \{intelligent tutoring systems, adaptive hypermedia, adaptive collaboration support $\}$ )

The detailed view of the facets incorporated in this paper is depicted in Fig. 3. These identified facets are used to compare 7 systems as discussed in the following section (Section 3 ).

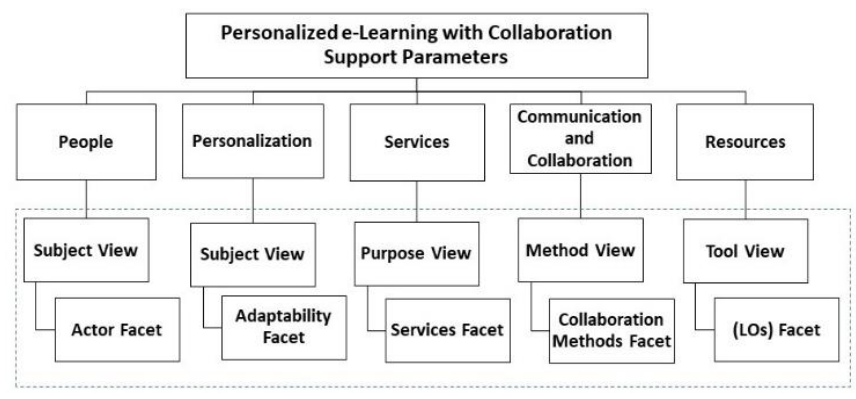

Fig. 2. Mapping the Personalized e-learning Parameters with the Classification Framework Views.

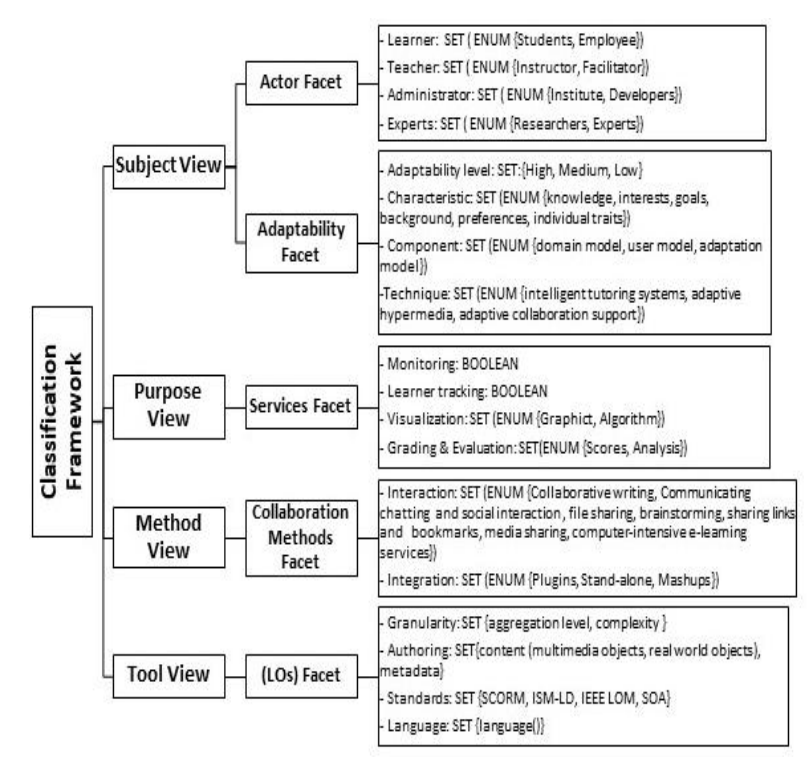

Fig. 3. Detailed Facets of the Classification Framework. 


\section{COMPARISON OF PERSONALIZED E-LEARNING WITH SOCIAL COLLABORATION SUPPORT}

As a reflection to the aim of the proposed classification framework discussed in this paper, seven systems have been selected to investigate the usefulness of the framework in giving the complete view on the targeted area of discussion. The selected systems are providing the personalization feature supported by social collaboration tools.

The systems selected for the comparison applying the proposed framework are presenting an attempt to add the social dimension by integrating web 2.0 functionalities with the adaptive/personalized learning techniques. The systems are WHURLE 2.0, SLAOS, GRAPPLE, Topolor, ALEF, SALT and Protus. The description of each of these systems and how social collaboration support is used for personalization are given below.

WHURLE 2.0 [34] consists of five independent Web services that collaborate with each other to tailor a unique view of the learning content for a given learner, and a delivery service (LMS) where the learner views this adaptive content. The framework incorporated Adaptive Educational Hypermedia Systems and web services (SOA). The WHURLE 2.0 has been tested for its adaptation and social collaborative interactive functionalities by providing it with the LMS's built-in tools such as a forum, chat, and wiki to perform the social activity. However, the aim of the study was only to investigate the extent to which students make use of the collaboration tools and if they aid in their learning process. Besides, the system separated the personalization and collaboration processes.

SLAOS [35] is a framework aiming to bring together three features which are; web 2.0, e-learning and adaptive personalization. The framework extended the adaptive hypermedia framework by integrating a social layer. This layer has features like collaborative authoring and social annotation. The authors' approach allows students to be part of the authoring stage but with some sets of privileges. The collaborative facilities in SLAOS rely on Web 2.0 techniques, such as group-based authoring, cooperation in creating the courses, tagging the content, and rating. However, the support provided on the domain modeling level and the ability to support collaboration based on user-generated content is limited.

GRAPPLE [36] is another framework that supports the learning process via (adaptive guidance and personalized content). The framework consists of two key components of which are GRAPPLE Adaptive Learning Engine (GALE), where the content adaptation is performed, and GRAPPLE User Modeling Framework (GUMF), in charge of managing user model data. LMS, GUMF, and GALE are communicated through GRAPPLE Event Bus (GEB). The framework aggregates and enriches the user modeling in GUMF by embodying Mypes service which exploits dataspaces to connect, aggregate, align and enrich user profile information from social media tools [37]. However, the focus was on the personal information located in the user profile which is not providing enough information about user knowledge and other characteristics.

Topolor [38], is a framework that introduces Web 2.0 tools into an adaptive educational hypermedia system. The framework is a layered based architecture consisting of two layers; storage layer and runtime layer. Topolor has a Facebook-like appearance and supports social annotation and collaborative learning by introducing the Affiliate Model. The framework provides a social e-learning environment, where learners can comment on a topic, ask or answer a question, create and share notes. It also supports learning content adaptation, learning path adaptation and peer adaptation. However, Topolor does not consider the use of data on preferred items for adaptation. Besides the framework considers the look of only one social interaction tool which is Facebook as a mean of a simple interaction between learners.

ALEF [39] is an Adaptive LEarning Framework. It is a framework for creating adaptive and highly interactive webbased learning systems. The system proposes a generic model, namely domain model, based on lightweight semantics which opens new possibilities of automated course metadata creation and student model. ALEF combines different learning activities (such as learning from explanatory texts, questions or exercises) along with the highly interactive and social environment of the Web 2.0. The framework provides personalized learning by recommending learning objects tailored to the student needs to be based on the student's knowledge. However, the framework suggested a limited number of social interaction mechanisms and it is not supporting the learning object authored by students.

SALT [40] is a framework for social learning which integrates social network functionality with traditional adaptive educational hypermedia to engage students into learning through teaching and adapt learning pathways to individual student needs based on collective learning experiences. The users (student and teacher) interact with each other by contributing to constructing a small learning content in the form of mini-lessons (lesslet). SALT implements selforganized personalization through learning pathways. However, the research focus is mainly on crowdsourcing and scalability issues like grouping students based on similar user's performance.

Protus (PRogramming TUtoring System) [41] is an intelligent web-based programming tutoring system. The system integrates collaborative tagging technique to provide personalized recommended learning resources. The tagging mechanism of the lessons adopted in the system provides information related to the learner's interest. This information is the key to identify the learning style. The system also uses a test to identify the knowledge level. Consequently, the learner's interest and previous knowledge level are used to provide personalized recommendations.

Table II summarizes the comparison between the above seven selected systems. The discussion on the finding is presented in the results and discussion section. 
TABLE. II. COMPARATIVE TABLE OF THE SELECTED SYSTEMS USING THE ClassificAtion Framework

\begin{tabular}{|c|c|c|c|c|c|c|c|c|c|c|c|c|c|c|c|c|c|c|}
\hline \multirow[b]{2}{*}{ System } & \multicolumn{4}{|c|}{ Actor } & \multicolumn{4}{|c|}{ Personalization } & \multicolumn{4}{|c|}{ Services } & \multicolumn{2}{|c|}{$\begin{array}{l}\text { Collaboration } \\
\text { method }\end{array}$} & \multicolumn{4}{|c|}{ Resource (LO) } \\
\hline & 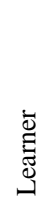 & 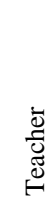 & 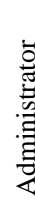 & 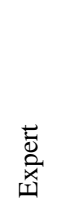 & 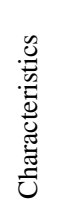 & 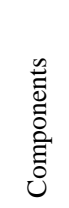 & 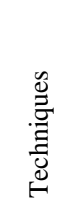 & $\begin{array}{l}\bar{d} \\
\text { d্] }\end{array}$ & 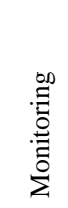 & 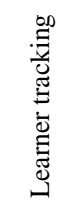 & 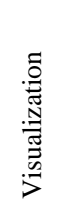 & 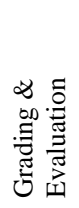 & 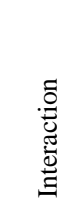 & 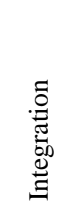 & 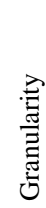 & 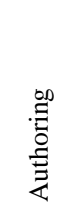 & 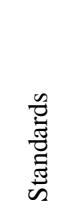 & 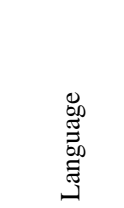 \\
\hline $\begin{array}{l}\text { WHURLE } 2.0 \\
\text { (2009) }\end{array}$ & S & I & In & $\mathrm{N}$ & K & $\mathrm{UM}$ & $\mathrm{AH}$ & $\mathrm{H}$ & MN & $\mathrm{N}$ & $\mathrm{N}$ & $\mathrm{Sc}$ & Co & PI & A & $\begin{array}{l}\mathrm{Cn}, \\
\mathrm{Md}\end{array}$ & SOA & $\begin{array}{l}\text { PHP } \\
\text { XML } \\
\text { XSLT }\end{array}$ \\
\hline $\begin{array}{l}\text { SLAOS } \\
(2011)\end{array}$ & S & I & $\mathrm{N}$ & Ot & $\mathrm{K}$ & UM & $\mathrm{AH}$ & $\mathrm{H}$ & MN & LT & $\mathrm{N}$ & $\begin{array}{l}\mathrm{Sc} \\
\mathrm{An}\end{array}$ & Co & SA & A & $\begin{array}{l}\mathrm{Cn}, \\
\mathrm{Md}\end{array}$ & $\mathrm{N}$ & $\begin{array}{l}\text { MySQL } \\
\text { CGI } \\
(\mathrm{C}++) \\
\text { RDF }\end{array}$ \\
\hline $\begin{array}{l}\text { GRAPPLE } \\
\text { (2012) }\end{array}$ & S & I & D & $\mathrm{N}$ & $\mathrm{K}$ & $\mathrm{UM}$ & $\mathrm{AH}$ & $\mathrm{H}$ & $\mathrm{N}$ & $\mathrm{N}$ & $\mathrm{G}$ & $\mathrm{Sc}$ & $\mathrm{N}$ & PI & A & $\begin{array}{l}\mathrm{Cn}, \\
\mathrm{Md}\end{array}$ & SOA & $\begin{array}{l}\text { XML } \\
\text { XHTML } \\
\text { RDF }\end{array}$ \\
\hline $\begin{array}{l}\text { Topolor } \\
\text { (2013) }\end{array}$ & S & I & $\mathrm{N}$ & $\mathrm{N}$ & $\begin{array}{l}K \\
P\end{array}$ & UM & $\mathrm{AH}$ & $\mathrm{H}$ & MN & LT & G & $\begin{array}{l}\mathrm{Sc} \\
\mathrm{An}\end{array}$ & Co & SA & A & $\begin{array}{l}\mathrm{Cn} \\
\mathrm{Md}\end{array}$ & $\mathrm{N}$ & $\begin{array}{l}\text { PHP } \\
\text { SQL }\end{array}$ \\
\hline $\begin{array}{l}\text { ALEF } \\
(2014)\end{array}$ & S & I & $\mathrm{N}$ & $\mathrm{N}$ & $\begin{array}{l}\text { K } \\
\text { GO }\end{array}$ & $\begin{array}{l}\mathrm{UM} \\
\mathrm{DM}\end{array}$ & $\mathrm{AH}$ & $\mathrm{H}$ & MN & $\mathrm{LT}$ & $\mathrm{G}$ & An & $\begin{array}{l}\text { Co } \\
\text { BK }\end{array}$ & SA & A & $\begin{array}{l}\mathrm{Cn} \\
\mathrm{Md}\end{array}$ & $\mathrm{N}$ & XML \\
\hline $\begin{array}{l}\text { SALT } \\
(2017)\end{array}$ & S & I & $\mathrm{N}$ & $\mathrm{N}$ & K & UM & $\begin{array}{l}\text { ITS } \\
\text { AH }\end{array}$ & $\mathrm{H}$ & MN & $\mathrm{N}$ & G & $\begin{array}{l}\mathrm{Sc} \\
\mathrm{An}\end{array}$ & $\begin{array}{l}\mathrm{CW} \\
\mathrm{Co}\end{array}$ & SA & A & $\begin{array}{l}\mathrm{Cn} \\
\mathrm{Md}\end{array}$ & $\mathrm{N}$ & $\begin{array}{l}\text { C\# } \\
\text { ASP.NET }\end{array}$ \\
\hline Protus (2018) & S & I & $\mathrm{N}$ & $\mathrm{N}$ & $\begin{array}{l}\mathrm{K} \\
\text { IT }\end{array}$ & UM & ITS & $\mathrm{H}$ & MN & $\mathrm{N}$ & $\mathrm{N}$ & An & BK & SA & A & $\begin{array}{l}\mathrm{Cn} \\
\mathrm{Md}\end{array}$ & $\mathrm{N}$ & Java \\
\hline
\end{tabular}

\section{TABLE II: (CONTINUED)}

Table Abbreviations: Subject View

- S: Student

- E: Employee

- I: Instructor

- F: Facilitator

- In: Institute

- D: Developer

- R: Researcher

- Ot: Outsider

- K: Knowledge

- IR: Interests

- GO: Goals

- B: Background

- P: preferences

- IT: Individual traits

- DM: Domain model

- UM: User model

- AM: Adaptation model

- ITS: Intelligent tutoring systems

- AH: Adaptive hypermedia

- ACLS: Adaptive collaboration support

- H: High

- M: Medium

- L: Low

- N: Not Applicable
Purpose View

- MN: Monitoring

- LT: Learner

tracking

- Vis:

Visualization (G:

Graphics, A:

Algorithm)

- G\&E: Grading \&

Evaluation (Sc:

Scores, An:

Analysis)

\section{Method View}

- CW: Collaborative writing

- Co: Communicate

- FS: File sharing

- BR: Brainstorming

- BK: Bookmarks

- MS: Media sharing

- EL: e-learning

- PI: Plugins

- SA: Stand-alone

- MA: Mashups
Tool View

- A: Aggregation level

- C: Complexity

- Cn: Content

- Md: Metadata

- SC: SCORM

- LD: ISM-LD

- LOM: IEEE LOM

- OS: OpenSocial 


\section{RESUlTS AND DISCUSSION}

The attempt to incorporate the social collaboration concept to provide the personalization feature is growing up among researchers in the educational field. However, while designing the systems, not all the required aspects have been considered. As illustrated in Table II, the finding of the comparison of the selected seven systems with respect to the four views can be summarized as follows:

\section{A. Subject View}

1) The main roles are played by the student as a learner and instructor as a teacher in all compared systems.

2) Most systems do not provide information related to the responsible party for managing the system except for WHURLE 2.0 and GRAPPLE.

3) Only SLAOS gives permission to an outsider to access the developed system.

4) All systems deliver a high level of personalization.

5) Most systems provide personalization based on one parameter which is the knowledge level except three of them which are Topolor, ALEF, and Protus.

6) Collaboration support has been utilized to generate/update the user model in all compared systems except the lightweight domain modeling proposed in ALEF. This indicates the limited support for semi/automatic construction of the domain model.

7) Most of the compared systems (85\%) use adaptive hypermedia $(\mathrm{AH})$ technique for personalization except for Protus which uses Intelligent tutoring technique (ITS).

8) An overall consideration of the facets (Actor \& Personalization) in subject view by compared systems is shown in Fig. 4. The figure illustrates the focus on the main actors of an e-learning environment which are the learner and teacher (41\% each) and less attention to expert (6\%) only. It also shows the high attention played by all systems in delivering personalization considering the four attributes representing the personalization facet.

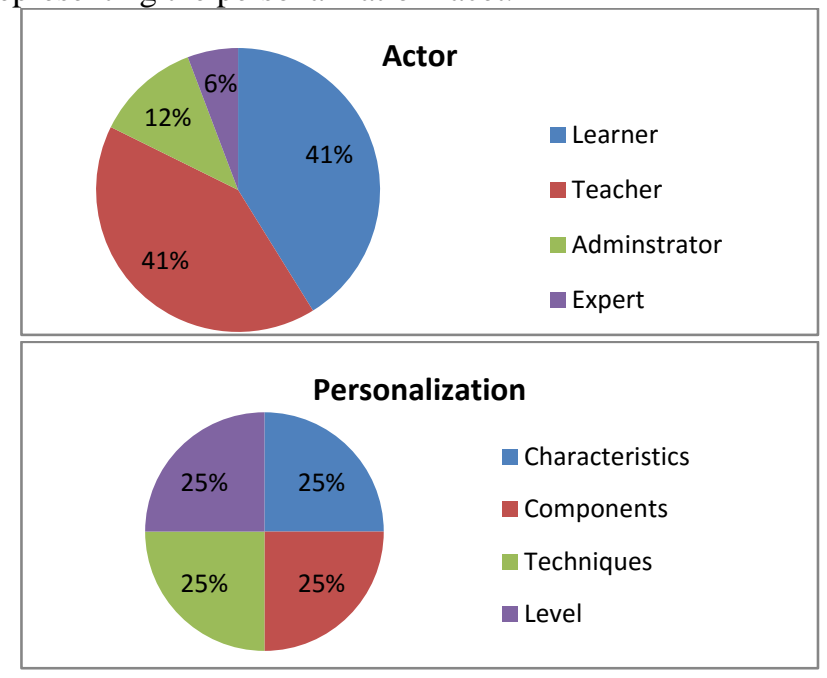

Fig. 4. Consideration of the Facets (Actor and Personalization) in the Subject View.

\section{B. Purpose View}

1) Almost $85 \%$ of the compared systems targeted monitoring $(\mathrm{MN})$ purpose and $40 \%$ targeted learner tracking (LT) purpose.

2) The visualization service provided by $57 \%$ of the compared systems was based on graphics visualization.

3) Both scores and analysis parameters were considered with respect to grading and evaluation service by compared systems either together as in SLAOS, Topolor, and SALT or one of the parameters.

4) The overall consideration of service fact is quite promising as depicted in Fig. 5. However, learning tracking attribute needs to be deliberated more to add more value to the developed system as it is currently getting the least attention (15\%) among other attributes in this fact.

\section{Method View}

1) Around $70 \%$ of the systems incorporated communication technique as an interaction method.

2) The integration of the collaboration method using a stand-alone technique is quite promising for data analysis in most systems especially by implementing semi-structured discussion as in Topolor, ALEF, and Protus. However, the data analysis by utilizing the user-generated content was limited.

3) As depicted in Fig. 6, the overall consideration of the Collaboration method facet in the method view is acceptable as both attributes almost equally considered (46\% interaction $\& 54 \%$ integration). However, there is a limited consideration in the values of the different attributes as shown in the comparison table (Table II).

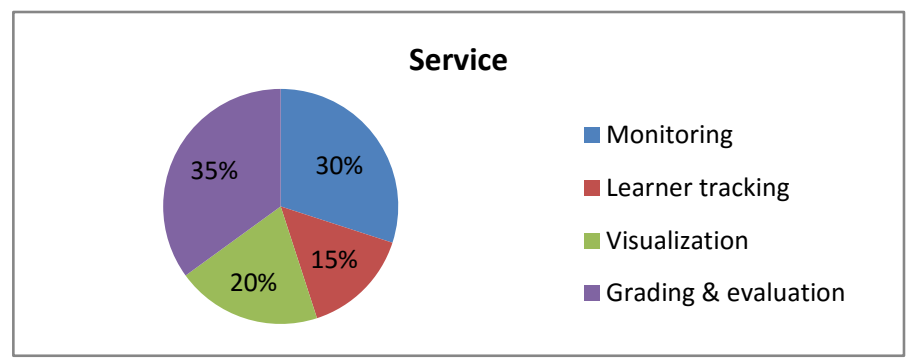

Fig. 5. Consideration of the Service Facet in the Purpose View.

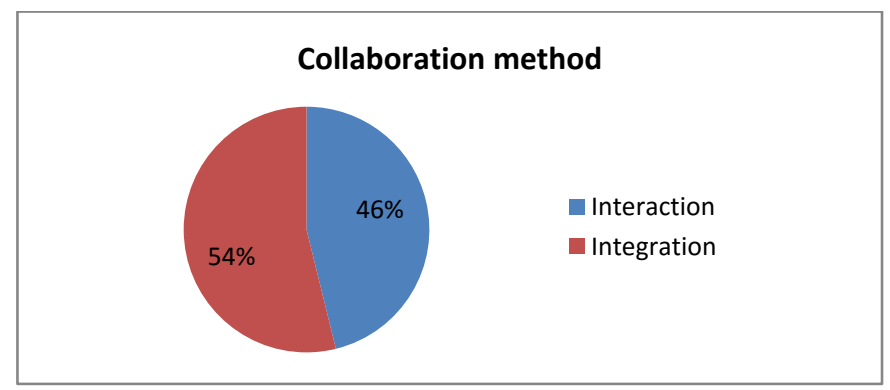

Fig. 6. Consideration of the Collaboration Method Facet in the Method View. 


\section{Tool View}

1) The aggregation has been considered for granularity by all compared systems.

2) Content as a mean of the multimedia object has been considered for granularity by all compared systems.

3) With respect to the standard used for development, no information has been provided by researchers except for WHURLE 2.0 and GRAPPLE; they adopt SOA.

4) Various languages have been used for the implementation of the compared systems depend on the suitability to the functionalities and the embedded environment.

5) The overall consideration of the different attributes of the resource (LO) facet as shown in Fig. 7 is quite good. However, there is a need to focus on adapting the learning resource development standards like SCORM, IMS-LD, IEE LOM and SOA [12] when developing the systems as it is presenting only $9 \%$ consideration.

The overall remarks concluded from the classification are quite inspiring. In short, there is an acceptable level of social interaction proposed by the studied systems in terms of the interaction methods and the tools used. However, utilization of the user-generated content and social interaction functionalities for personalization is tight and not fully consumed. For instance, it is used to update one parameter of personalization and only one researcher used it for domain model construction. In fact, the potential of providing personalized learning based on social interaction and collaboration features remains not fully explored. The main issues which are required to be addressed in future systems based on the findings are:

1) Provide personalization based on more than one parameter, for example, the knowledge level and individual traits (Learning style).

2) The parameters (Knowledge level and learning style) could be obtained from user-generated content during collaboration.

3) Collaboration support can be the source to generate/update the user model and the construction of the domain model.

4) Provide a semi/structure collaboration tool to facilitate the ongoing discussions as in Topolor, ALEF, and Protus.

5) The integration of LMS is advisable to provide personalized e-learning environment within the commonly used environment for learning as incorporated by WHURLE 2.0 and GRAPPLE.

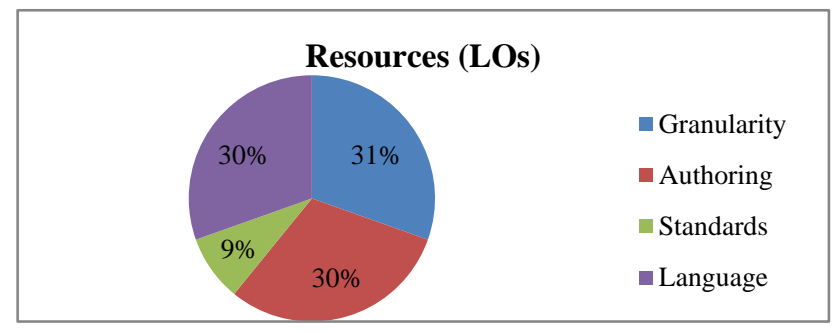

Fig. 7. Consideration of the Resource (LOs) Facet in the Tool View.

\section{CONCLUSION AND FUtURE WORK}

Applying the social dimension with adaptive learning by integrating Web 2.0 functionalities is the core concept to be studied in the era of the digital age. Therefore, understanding the adoption of personalized e-learning environment with the support of social collaboration tools is required for further development and upgrading. Despite the attempts carried out by different researchers to review the current status of personalized e-learning environments, they are targeting only a specific domain. Consequently, lacking provides a general or detailed view of the adoption of collaboration tools in this field. This paper gives a classified view of the current status of personalized e-learning environments which incorporates social collaboration tools for providing the personalization feature. The view classified the studied systems using four views: subject, purpose, method, and tool which gives a more comprehensive overview of the systems' functionalities. The comparison of the seven selected systems shows that the adoption of social interaction and collaboration tools is quite good in the educational field. It also shows that the utilization of the user-generated contents and social interaction functionalities for personalization is tight and not fully consumed. In general, the potential of providing personalized learning with social interaction and collaboration features remains not fully explored. The results indicate the importance of utilizing these remarks to achieve more advanced personalized e-learning systems.

Therefore, tackling the unconsumed functionalities like the utilization of user-generated contents during social interaction for personalization purpose is tagged as our future work. Besides, the flexible proposed framework can be expanded to cover more technical dimensions like the techniques and algorithms used for analyzing the social collaboration context towards personalization.

\section{ACKNOWLEDGMENT}

This work is supported by the Ministry of Manpower, Sultanate of Oman.

\section{REFERENCES}

[1] B. Phillips, "Beyond Classroom Learning: Personalized Learning Through Digital Technologies," 2016.

[2] M. Kravcik, O. C. Santos, and J. G. Boticario, "4th International Workshop on Personalization Approaches in Learning Environments (PALE 2014)," 2014.

[3] L. Johnson, S. Adams Becker, M. Cummins, V. Estrada, A. Freeman, and C. Hall, "NMC Horizon Report: 2016 Higher Education Edition," Austin, Texas New Media Consort., 2016.

[4] J. Heller, C. Steiner, C. Hockemeyer, and A. Dietrich, "Competencebased knowledge structures for personalised learning," Int. J. ELearning, vol. 5, no. 1, p. 75, 2006.

[5] F. Mödritscher and F. Wild, "Personalized e-learning through environment design and collaborative activities," in Symposium of the Austrian HCI and Usability Engineering Group, 2008, pp. 377-390.

[6] Y. Jamoussi, Z. Al-khanjari, and N. Kraiem, "A Framework to Evaluate E-learning Based on Social Networking," vol. 2, no. 4, pp. 26-42, 2014.

[7] A. Al-Abri, Z. Al-Khanjari, N. Kraiem, and Y. Jamoussi, "A scheme for extracting information from collaborative social interaction tools for personalized educational environments," in Proceedings of the IEEE International Conference on Computing, Networking and Informatics, ICCNI 2017, 2017, vol. 2017-Janua. 
[8] A. Al-Abri, Y. Jamoussi, N. Kraiem, and Z. Al-Khanjari, "Comprehensive classification of collaboration approaches in Elearning," Telemat. Informatics, vol. 34, no. 6, 2017.

[9] Z. Al-Khanjari, Y. Al-Roshdi, and N. Kraiem, "Virt-res: Developing extended architectural design for computer science virtual resources using SOA,” Int. J. Softw. Eng. Its Appl., vol. 8, no. 9, pp. 125-136, 2014.

[10] E. Popescu, "Providing collaborative learning support with social media in an integrated environment," World Wide Web, vol. 17, no. 2, pp. 199-212, 2014.

[11] P. Dillenbourg, S. Järvelä, and F. Fischer, "The evolution of research on computer-supported collaborative learning," in Technology-enhanced learning, Springer, 2009, pp. 3-19.

[12] A. Al-Abri, Z. Al-Khanjari, Y. Jamoussi, and N. Kraiem, "Developing a Collaborative Learning Environment Using Web Services Techniques.," JSW, vol. 11, no. 9, pp. 870-882, 2016.

[13] Z. Du, X. Fu, C. Zhao, Q. Liu, and T. Liu, "Interactive and collaborative e-learning platform with integrated social software and learning management system," in Proceedings of the 2012 International Conference on Information Technology and Software Engineering, 2013, vol. 212, pp. 11-18.

[14] M. Masud, "Collaborative e-learning systems using semantic data interoperability," Comput. Human Behav., vol. 61, pp. 127-135, 2016.

[15] A. Al-Abri, Z. Al-Khanjari, Y. Jamoussi, and N. Kraiem, "Identifying Learning Styles from Chat Conversation using Ontology-Based Dynamic Bayesian Network Model," in 2018 8th International Conference on Computer Science and Information Technology (CSIT), 2018, pp. 1-8.

[16] Z. A. Al-Khanjari, "Developing a common personalization framework for the e-application software systems," J. Emerg. Technol. Web Intell., vol. 5, no. 2, pp. 188-195, 2013.

[17] N. Dabbagh and A. Kitsantas, "Personal Learning Environments, social media, and self-regulated learning: A natural formula for connecting formal and informal learning," Internet High. Educ., vol. 15, no. 1, pp. $3-8,2012$.

[18] A. Kahaei, "Design of Personalization of Massive Open Online Courses," 2014.

[19] J. Heller, B. Mayer, and D. Albert, "Competence-based knowledge structures for personalised learning," in 1st International ELeGI Conference on Advanced Technology for Enhanced Learning, 2005, p. 8.

[20] D. Hauger and M. Köck, "State of the Art of Adaptivity in E-Learning Platforms.," in LWA, 2007, pp. 355-360.

[21] C. Limongelli, F. Sciarrone, and G. Vaste, "Personalized e-learning in moodle: The moodle_LS system," J. E-Learning Knowl. Soc., vol. 7, no. 1, pp. 49-58, 2011.

[22] J. Broadbent and W. L. Poon, "Self-regulated learning strategies \& academic achievement in online higher education learning environments: A systematic review," Internet High. Educ., vol. 27, pp. $1-13,2015$.

[23] K. Colchester, H. Hagras, D. Alghazzawi, and G. Aldabbagh, "A survey of artificial intelligence techniques employed for adaptive educational systems within e-learning platforms," J. Artif. Intell. Soft Comput. Res., vol. 7, no. 1, pp. 47-64, 2017.
[24] W. Denton, "How to make a faceted classification and put it on the web," Online (November 2003) http//www. miskatonic. org/library/facet-web-howto. html, 2003.

[25] O. Saidani, R. S. Kaabi, N. Kraiem, and Y. Baghdadi, "A multidimensional framework to classify goal-oriented approaches for services," in Computer Applications Technology (ICCAT), 2013 International Conference on, 2013, pp. 1-5.

[26] D. Gillet, "Personal learning environments as enablers for connectivist MOOCs," in Information Technology Based Higher Education and Training (ITHET), 2013 International Conference on, 2013, pp. 1-5.

[27] Becta, "Learning platforms and personalising learning. An essential guide." p. 6, 2007.

[28] Z. A. Al-Khanjari and N. S. Kutti, "Re-Engineering Learning Objects for Re-Purposing," Int. J. Eng. Res. Appl., vol. 4, no. 8, pp. 103-111, 2014.

[29] K. Anandakumar, K. Rathipriya, and A. Bharathi, "A survey on methodologies for personalized e-Learning recommender systems," Int. J. Innov. Res. Comput. Commun. Eng., vol. 2, no. 6, 2014.

[30] E. Kurilovas, S. Kubilinskiene, and V. Dagiene, "Web 3.0-Based personalisation of learning objects in virtual learning environments," Comput. Human Behav., vol. 30, pp. 654-662, 2014.

[31] P. Brusilovsky and E. Millán, "User models for adaptive hypermedia and adaptive educational systems," in The adaptive web, Springer, 2007, pp. 3-53.

[32] P. De Bra and J.-P. Ruiter, "Aha! adaptive hypermedia for all," Proc. AACE WebNet Conf., no. DECEMBER 2001, pp. 262-268, 2001.

[33] P. Brusilovsky, "Adaptive educational systems on the world-wide-web: A review of available technologies," in Proceedings of Workshop" WWW-Based Tutoring" at 4th International Conference on Intelligent Tutoring Systems (ITS'98), San Antonio, TX, 1998.

[34] M. Meccawy, "A service-orientated architecture for adaptive and collaborative e-learning systems .," University of Nottingham, 2009.

[35] A. I. Cristea and F. Ghali, "Towards Adaptation in E-Learning 2 . 0," 2010.

[36] P. De Bra et al., "GRAPPLE Learning Management Systems Meet Adaptive Learning Environments.pdf," Intell. Adapt. Educ. Syst., pp. 133-160, 2013.

[37] F. Abel, N. Henze, E. Herder, G.-J. Houben, D. Krause, and E. Leonardi, "Building blocks for user modeling with data from the social web," CEUR Workshop Proc., vol. 609, 2010.

[38] L. Shi, A. I. Cristea, J. G. K. Foss, D. Al Qudah, and A. Qaffas, “A social personalized adaptive e-learning environment: a case study in topolor," vol. 7641, pp. 1-17, 2013.

[39] M. Bielikovà et al., "ALEF: From application to platform for adaptive collaborative learning," Recomm. Syst. Technol. Enhanc. Learn. Res. Trends Appl., no. 1, pp. 195-225, 2014.

[40] E. Karataev and V. Zadorozhny, "on Crowdsourcing," vol. 10, no. 2, pp. 128-139, 2017.

[41] A. Klašnja-Milićević, M. Ivanović, B. Vesin, and Z. Budimac, "Enhancing e-learning systems with personalized recommendation based on collaborative tagging techniques," Appl. Intell., vol. 48, no. 6, pp. 1519-1535, 2018. 